PHYSCAL EDUCATON, FITESSANDSPORTS

\title{
Technology consideration in tennis umpiring: replacing the humans
}

\author{
Jan Carboch ${ }^{a, *}$ \\ a Faculty of Physical Education and Sport, Charles University, José Martího 31, Prague 6, 162 52. Czech Republic. \\ *Corresponding author Email: carby@post.cz \\ DOI: https://doi.org/10.34256/ijpefs2141
}

Received: 06-09-2021, Revised: 30-09-2021; Accepted: 02-10-2021; Published: 04-10-2021

\begin{abstract}
New technologies step into sports refereeing, officiating, or umpiring. This technology can assist humans to avoid blunders or errors. However, in tennis, this technology now starts to replace humans, i.e. the line umpires. In this letter, we try to provide insight into potential problems, that this technology brings, but also we try to provide its benefits. We offer considerations from the umpire (human) view. It is not very clear and we consider it still in a grey zone, what are the next best steps, even though it seems that the new technology implementation is unavoidable. In this letter, we focus on tennis line umpires, because technology is replacing them now. Therefore, would like to encourage and call for more research on this currently hot topic.
\end{abstract}

Keywords: Referee, Officiating, Umpire, Accuracy, Errors, Decision-making

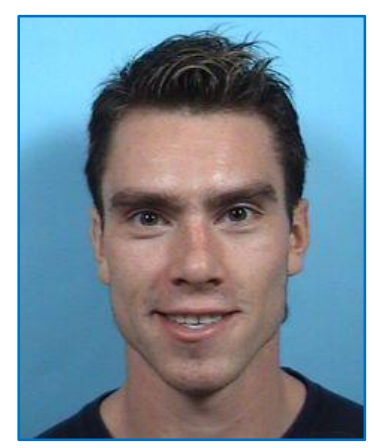

Dr. Jan Carboch, Ph.D. is a lecturer and scientist at the Department of Sports Games, Faculty of Physical Education and Sport, Charles University in the Czech Republic. He graduated and finished his PhD. at the same University. His dissertation thesis was focused on visual perception and anticipation in tennis. His research interest includes performance analyses in sports games, anticipation and visual perception in tennis, and qualitative analyses of human movement.

\section{Introduction}

In past years new technologies stepped into professional sport. In tennis, a Hawk-Eye system has been used to check the line umpires' calls. Video assistants are now used in football matches to review various situations. These technologies can be seen in many professional sports events in many sports, e.g. cricket, baseball, rugby, ice hockey, and seem to be beneficial as they can correct human errors of an official, umpire, or referee. In sports such as football, this video technology assists the referee to make decisions, correct his decision, or avoiding blunders. While it is transparent, and the rules about applying them are clear, the technology in such situations will probably be beneficial. However, there are still some controversies, in general, a lot of inaccurate situations can be avoided with the help of this technology [1]. The use of this technology seems to be helpful and within the interest of the sports and fans. Researchers are also involved in this new field and already some studies were conducted [2]. Despite these new technologies are seemingly being beneficial, as it has appeared in tennis, where humans are being replaced by that technology.

Most of the people following tennis know that chair and line umpires are officiating the top matches. Some disputes or controversial situations happen when a ball bounce close to the line. When Electronic line calling (ELC) is available (e.g. Hawk-Eye system), a player can challenge the call. However, this technology is now set up and starts to replace the line umpires at the level of professional tournaments such as Grand slams e.g. US Open. However, Wimbledon 2021 kept the line umpires. This letter aims to try to think about whether we want, or we need to make this replacement.

\section{Technology or umpire (human)?}

In all probability, a lot of money and effort has been invested into the ELC live technology. The 
question is why it should or should be not brought into the sports environment. It may be tough to answer that question as at the moment the Covid situation helped to apply this technology faster on the court while traveling and gathering people was restricted. Of course, in terms of organizers economically, it may be more convenient and more affordable to use ELC live in the big tournaments, because they don't need to pay huge amounts of line umpires, their travels, meals, and accommodation. Also, we don't see the philosophy and inner interests of the governing bodies of the ITF, WTA, and ATP organizations. There is another important issue to discuss and that is accuracy.

The ELC is very accurate requiring proper calibration, which is necessary for its proper working (this proper calibration process can still be sometimes an issue, as the top line umpires sometimes disagree with the system outcome). The margin error of these systems is $2-3 \mathrm{~mm}$, which is quite accurate. Humans are less accurate reaching bigger errors however their performance is more than sufficient. The errors are detected by the ELC and the error rate is $20-30$ percent of the challenged calls which and on average, an error occurs every 17 games, which is less than 1 error per set [3]. For tennis fans, the Hawk-eye system brings emotions, tension and also it improves their experience $[4,5]$, which will be eliminated by the ELC live. Do we need better accuracy at the expense of attractivity and emotions?

\section{Officiating system and line umpires' development}

Another point is that removing the line umpires from the top tournaments can destroy the whole officiating system, as recruiting new line umpire officials will be more difficult and the level of line umpiring will drop down. Moreover, most chair umpires are recruited from the line umpires. There will be a need for line umpires in the minor tennis tournaments still (as the technology would be too expensive compared to smaller number of line umpires). However, the line umpires will have less motivation of self-improvement to work in tennis and to reach the top tournaments and officiate the best players. Another thing is that people are going to lose their jobs or chance to earn money [6]. Is this what society wants?

\section{What is next?}

However, we have reached the breaking point, where we need to decide if we want or need to replace the line umpires in tennis. This text raises some questions, pros and cons. The point of this letter is to ask and encourage scientists from various fields such as sport analyses, psychology, sociology, economy, and others involved in this interdisciplinary problem, to step in and to perform studies involving these problematics in tennis to help answer all the raised questions so that the sports society and organizations can have some theoretical framework to base their decisions in applying this technology instead of humans. Some of these issues may apply to other sports.

\section{Conclusion}

There are pros and cons to the new technology implementation. This technology brings some benefits to various sports as it assists in decisions made by humans. However, tennis is one of the first sports, where technology starts to replace humans. We raised some questions and provided thoughts, which can be used for further consideration or analysis. Therefore, we would like to call for more research in this field and in this booming topic.

\section{References}

[1] P. Jonck, J. Surujlalb, M. Dhurup, Perception of and Satisfaction with Video Assistant Refereeing in Soccer, International Journal of Innovation, Creativity and Change, 14(9) (2020) 677-691.

[2] J. Zglinski, Rules, Standards, and the Video Assistant Referee in Football, Sport, Ethics and Philosophy, (2020) 1-17. [DOI]

[3] J. Carboch, K. Vejvodova, \& V. Suss, Analysis of errors made by line umpires on ATP tournaments, International Journal of Performance Analysis in Sport, 16(1) (2016) 264-275. [DOI]

[4] N. Anbarci, J. Lee, \& A. Ulker, Win at All Costs or Lose Gracefully in High-Stakes Competition? Gender Differences in Professional Tennis, Journal of Sports Economics, 17(4) (2014) 323-353. [DOI]

[5] O. Kolbinger, \& M. Knopp, Video kills the sentiment-Exploring fans' reception of the video assistant referee in the English premier league using Twitter data, PLOS ONE, 15(12) (2020). [DOI]

[6] S. Achieng, C.M. Majuto, P. Aseka, \& E. Astiaya, Replacing Humans with Machines: Threats and Opportunities, East African Journal of Business and Economics, 1(2) (2019) 54-68. 


\section{Funding}

No funding was received for conducting this study.

\section{Conflict of interest}

The Author has no conflicts of interest to declare that they are relevant to the content of this article.

\section{Does this article screened for similarity?}

Yes

\section{About The License}

(C) The Author 2021. The text of this article is open access and licensed under a Creative Commons

Attribution 4.0 International License 